๑๑ Entomologica Fennica. 8 January 1998

\title{
Five new species of Platygastroidea from Norway (Hymenoptera)
}

\author{
Peter Neerup Buhl
}

Buhl, P. N. 1998: Five new species of Platygastroidea from Norway (Hymenoptera). — Entomol. Fennica 8: 197-204.

Five new species are described from Southern Norway, viz. Telenomus ciliatus sp. n. ( $\left.\sigma^{\top}\right)$, Synopeas brevis sp. n. (O) (also from the United Kingdom), S. bohemani sp. n. $\left(Q, \mathrm{O}^{7}\right)$, Platygaster litoralis sp. n. $\left(\mathcal{Q}, \mathrm{O}^{7}\right)$, and Prosactogaster

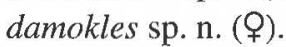

Peter Neerup Buhl, Parmagade 36, st.tv., DK-2300 Copenhagen S, Denmark

Received 19 June 1996, accepted 14 August 1997

During my survey of Norwegian Proctotrupoidea s.l. based on material sent to me by Mr. Lars Ove Hansen at the Zoological Museum in Oslo (ZMO), numerous species new to science appeared, five of which are described below.

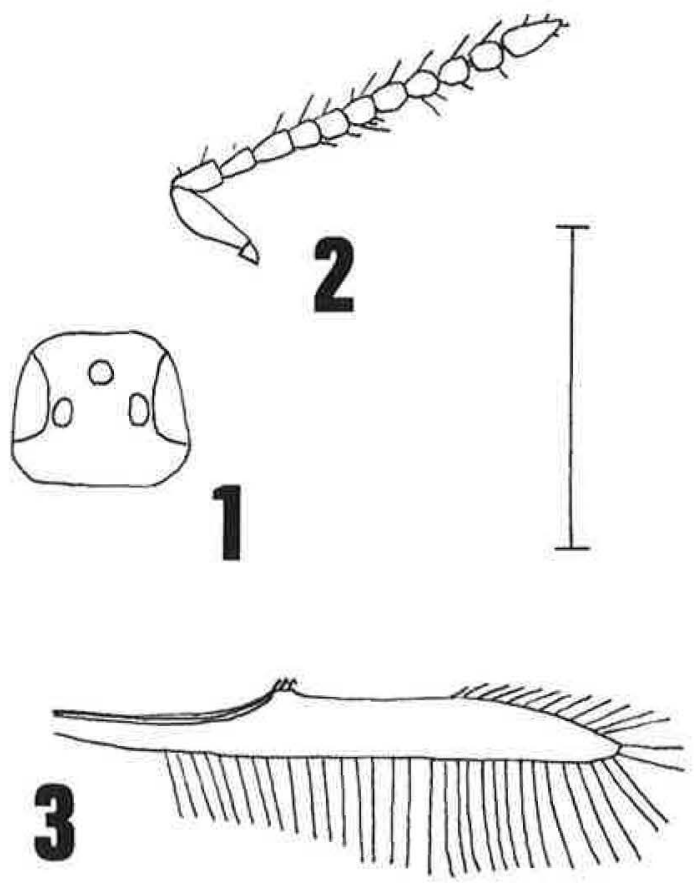

Figs. 1-3. Telenomus ciliatus sp. $\mathrm{n}$. ơ: 1: Head from above; 2: Antenna; 3: Hind wing. Scale bar $=0.25 \mathrm{~mm}$.
Family Scelionidae (subfam. Telenominae)

Telenomus ciliatus sp. $\mathrm{n}$.

Figs. 1-3

Type material: Holotype ơ in ZMO labeled "Norway EIS 28, AK, Asker: Biørkås 2 July-24 Aug. 1995. L.O. Hansen/ O. Hanssen, Malaise trap". Unique.

Diagnosis. - A most distinct species with head only slightly wider than long; marginal cilia of fore wing two-thirds, of hind wing about twice the width of the wing; body length only $0.5 \mathrm{~mm}$.

Description of holotype. - o . Body length $0.5 \mathrm{~mm}$. Colour blackish brown; legs light brown, most of femora and tibiae, and antennae and mandibles somewhat darker.

Head from above (Fig. 1) 1.2 times wider than long, about as wide as thorax; occiput without carina, transversely reticulate; vertex with faint reticulation; frons almost smooth with some fine punctures, and above antennal insertions with rugosity. Head from in front about as high as wide; malar space about 0.4 the height of an eye; lateral ocelli almost touching inner orbits. Antenna (Fig. 2) with scape only half as long as height of head; A11 hardly longer than wide.

Mesosoma almost 1.6 times longer than wide and 1.2 times wider than high, rather flattened. Pronotum, mesoscutum and mesopleurae with some reticulation, scutellum smooth. 


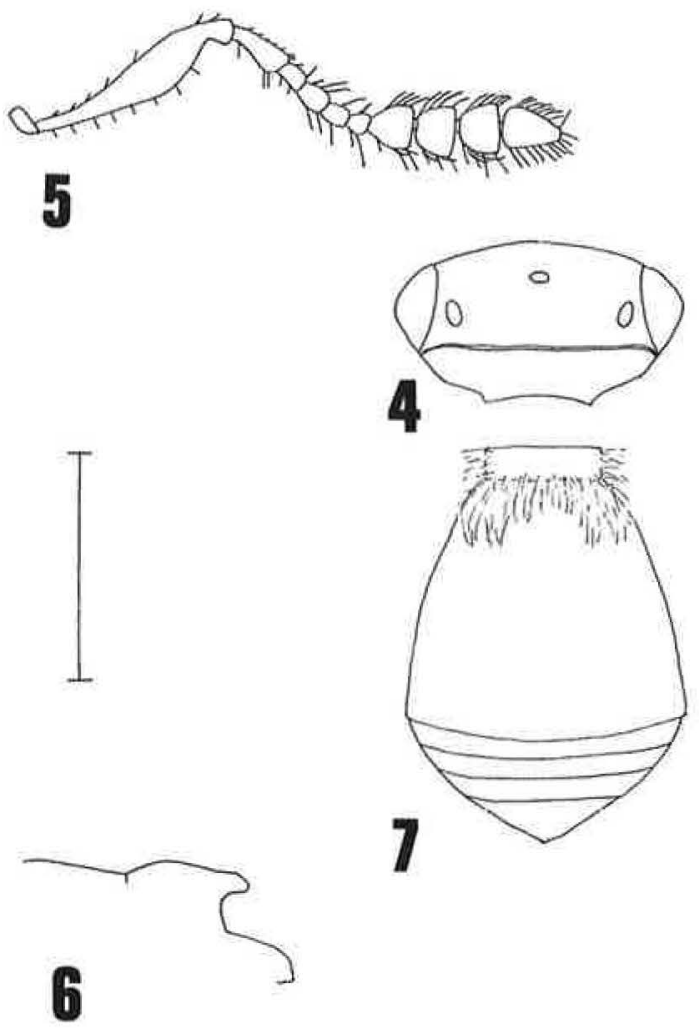

Figs. 4-7. Synopeas brevis sp. n. \%: 4: Head from above; 5: Antenna; 6: Scutellum in lateral view; 7: Metasoma from above. Scale bar $=0.25 \mathrm{~mm}$.

Fore wing clear, 3.0 times longer than wide; venation very pale; stigmalis short, hardly onethird the length of postmarginalis; marginal cilia two-thirds the width of the wing. Hind wing (Fig. 3) with marginal cilia almost twice the width of the wing.

Metasoma slightly shorter than mesosoma (8:9) and 0.75 times as wide. T1 smooth, faintly crenulate; T2 hardly longer than wide, basal striae about as long as $\mathrm{T} 1$; rest of tergites combined slightly shorter than T2, smooth, with a few long hairs.

Affinities. - Among Palaearctic species most similar to T. minimus Kozlov, 1967, but this species has slightly shorter marginal cilia of the hind wings and the head is 1.7 times wider than long, cf. Kozlov and Kononova (1983). Also rather similar to T. heteropterus Haliday, 1833, but this species has a head about 1.5 times wider than long, distinctly shorter marginal cilia of wings, and it is somewhat larger (about $0.75 \mathrm{~mm}$ ), cf. Huggert (1983). T. microceps Szabó, 1978 has a head as long as wide, legs except tarsi black, and mesoscutum strongly convex; length: $0.8 \mathrm{~mm}$ (ㅇ), cf. Szabó (1978). T. albatorius Kozlov \& Kononova, 1987 is also small and has very long marginal cilia of the hind wing, but this species has a head 2.1 times wider than long, cf. Kozlov and Kononova (1987). The two Neotropical species T. cubiceps Ashmead, 1894 and T. zethos Walker, 1836 are almost similar to ciliatus in the size and the shape of the head, but cubiceps has A4-A11 of male antenna twice as long as wide, and zethos has slightly different antennal structure, and yellow antenna and pale yellow legs, cf. Kieffer (1926).

Family Platygastridae (subfam. Platygastrinae)

Synopeas brevis sp. n.

Figs. 4-7

Type material: Holotype $\odot$ in ZMO labeled "Norway Eis 28, AK, Asker: Bjørkås 2 July-24 Aug. 1995. L.O. Hansen/ O. Hanssen, Malaise trap". Paratypes (3 ㅇ): 2 \%, Norway (EIS 97), NTI, Mosvik, Kilen 25.VII.-14.VIII.1994, Malaise trap, Norwegian Institute for Nature Research leg.; 1 \&, United Kingdom, Abbots Moss (grid ref.: SJ596680) 12.X.1990-10.I.1991, Malaise trap by stream, David G. Notton leg. All paratypes in the Zoological Museum, University of Copenhagen.

Diagnosis. - Belongs to Synopeas s. str.; occipital carina strong; A3-A4 and A8-A9 short; notauli wanting; scutellar spine distinct; fore wings with short marginal cilia; metasoma short, T6 much transverse; legs uniformly bright orange.

Description of holotype. - ㅇ. Body length $1.0 \mathrm{~mm}$. Colour black; scape and legs except last segment of tarsi bright orange; A2-A6 of antennae slightly darker, A7-A10 and mandibles dark brown.

Head entirely reticulate, from above (Fig. 4) 1.9 times wider than long, hardly wider than thorax; occiput with strong carina. Head from in front 1.2 times wider than high; malar space about onethird the height of an eye; OOL:POL:LOL = 1:14:7. Antenna (Fig. 5) rather hairy, with A2 slightly longer than A3-A4 combined; A8-A9 each distinctly transverse.

Mesosoma 1.4 times longer than wide and 1.1 times higher than wide. Sides of pronotum sparse- 
ly hairy in upper 0.4 , faintly reticulate except along hind margin. Mesoscutum rather sparsely hairy, reticulate, without trace of notauli, hind margin slightly prolonged and brownish medially, reaching base of scutellum; scuto-scutellar grooves covered by dense hairs. Mesopleurae smooth. Scutellum (Fig. 6) slightly convex, smooth and sparsely hairy medially, densely hairy laterally, spine brownish. Metapleurae smooth and bare along anterior margin, rest with white pilosity. Propodeal carinae fused.

Fore wing clear, densely hairy all over, 2.2 times longer than wide; marginal cilia at their longest about 0.1 the width of the wing. Hind wing 5.0 times longer than wide; marginal cilia 0.4 the width of the wing.

Metasoma (Fig. 7) hardly narrower than mesosoma and as long, 1.4 times wider than high. Hind margin of $\mathrm{T} 2$, which is otherwise smooth, and T3T5 each with a transverse strip of reticulate microsculpture, T6 with microsculpture all over, T3T6 with a few short hairs.

Affinities. - Runs to S. trebius (Walker, 1835) and $S$. velutinus (Walker, 1835) in Vlug's (1985) key, but trebius has a more transverse head, head entirely pustulated, junction of $\mathrm{T} 1$ and $\mathrm{T} 2$ with three strong carinae, and hind femora and tibiae distally black; velutinus has notauli present in their posterior half, A3-A5 and A7-A 8 more slender than in brevis, scutellum slightly below level of mesoscutum, and middle and hind femora darkened, cf. Vlug (1985). Of the species treated by Thomson (1859), brevis is most similar to S. affinis (Nees, 1834), but this species is larger $(1.6 \mathrm{~mm})$, it has yellow legs with femora and tibiae darkened apically, notauli indicated, and a scutellar spine different than in brevis, cf. Kieffer (1926) and Kozlov (1978).

\section{Synopeas bohemani sp. $\mathrm{n}$.}

Figs. 8-12

Type material: Holotype in ZMO labeled "Norway EIS 28, AK, Oslo: Østensiø 20 August 1888. Leg. Hans Kiær (1276a)". - Paratypes (1 O, $\left.20^{\circ}\right): 1 \%$ in ZMO labeled "Norway EIS 37, AK, Sørum: Lørenfallet, Egner August 1994. L. O. Hansen \& O. Sørlibråten. Malaise-trap"; 107 in ZMO labeled "Tromöy, 18.7.1953, leg. A. Bakke"; 1 o" in the Zoological Museum, University of Copenhagen labeled "Norway EIS 11, TEY, Bamble: Langøya 6-31 July 1995. Lars O. Hansen/R. Mehl. Malaisetrap pineforest".
Diagnosis. - Belongs to Synopeas s. str.; a very characteristic species on account of a rather thick head with distinct occipital carina, entirely orange-yellow legs, and total lack of notauli and of marginal cilia on fore wings.

Description. - . . Body length $1.4 \mathrm{~mm}$. Colour dark brown (holotype) to black; antennae except A7-A10, mandibles and legs entirely orange-yellow.

Head dull, evenly and finely reticulate, from above (Fig. 8) 1.7 times wider than long, very slightly narrower than thorax, occipital carina weak but almost complete; head from in front hardly wider than high, malar space hardly 0.4 the height of an eye; OOL:POL:LOL = 5:21:10. Antenna (Fig. 9) with A4 1.5 times longer than A3, 2.7 times longer than wide; A7-A9 each about as wide as long.

Mesosoma slightly higher than wide (17:16) and almost 1.4 times longer than wide. Sides of pronotum moderately hairy and weakly reticulate in upper 0.6 , along hind margin and in lower 0.4 smooth, with a few hairs. Mesoscutum moderately hairy, finely and weakly reticulate (smoother than head), without trace of notauli, hind margin semitransparent and slightly prolonged medially, reaching base of scutellum. Mesopleurae smooth and bare except for a few short and weak longitudinal striae in upper posterior corner. Scutellum (Fig. 10) smooth, moderately hairy medially, densely hairy laterally, spine and lamella below it semitransparent light brown. Metapleurae smooth and bare along upper and lower margins and in anterior third, rest with dense white pilosity, sides of propodeum with dense white pilosity; propodeal carinae semitransparent brown, fused.

Fore wing clear, rather densely hairy, hardly 0.9 times as long as whole body and two and a third times longer than wide; marginal cilia absent. Hind wing 5.1 times longer than wide; marginal cilia one-fourth the width of the wing.

Metasoma (Fig. 11) slightly wider than mesosoma (17:16) and 1.2 times longer, and 1.7 times wider than high. T1 and base of T2 with dense white pubescence; T2 smooth; T3-T5 each with a transverse strip of rugosity along hind margin, T4-T5 each also with a transverse row of short and superficially implanted hairs; T6 with rugosity except along anterior margin.

o. Body length 1.0-1.2 mm. Body colour slightly darker than in female holotype; antennae 


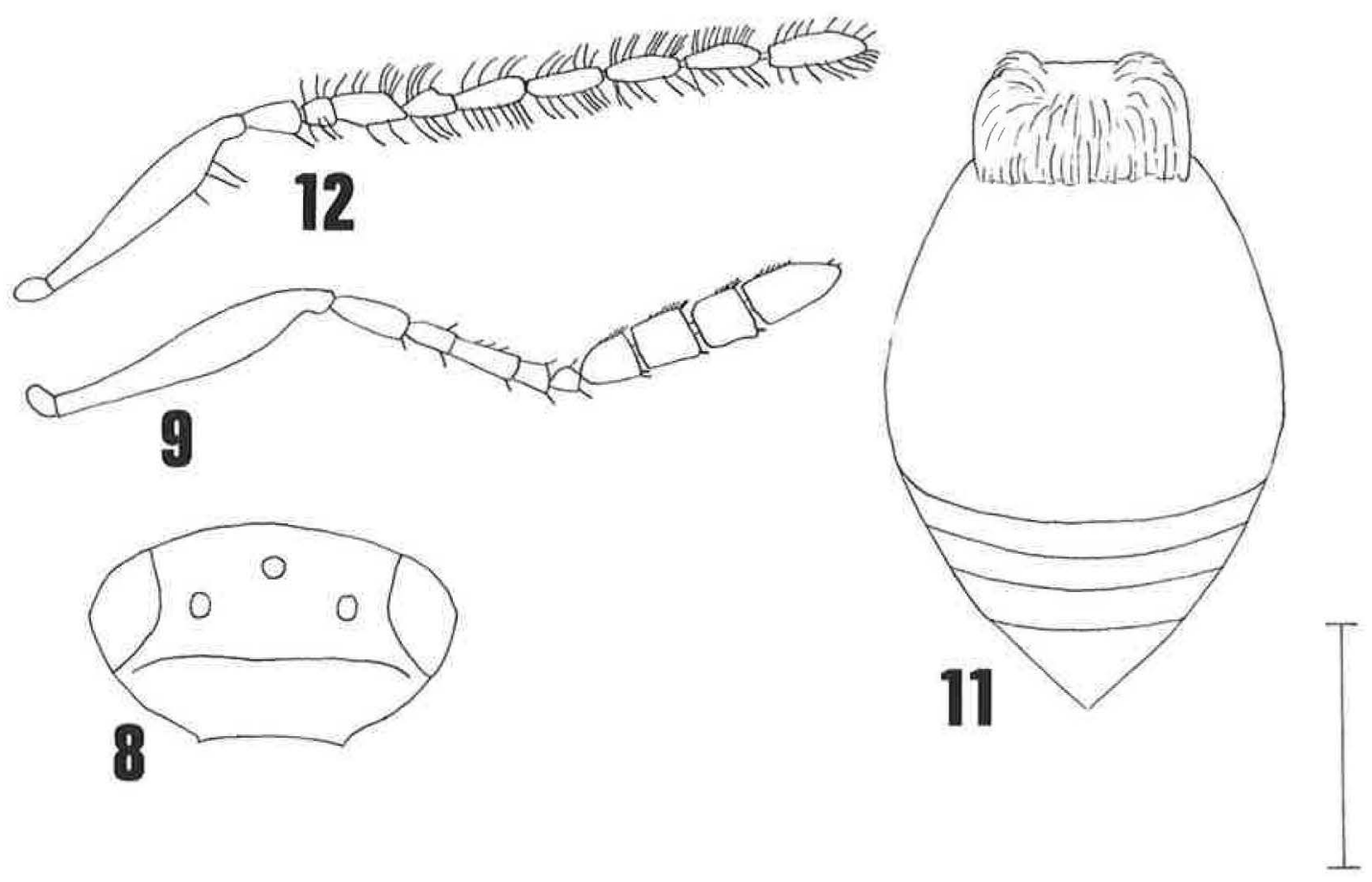

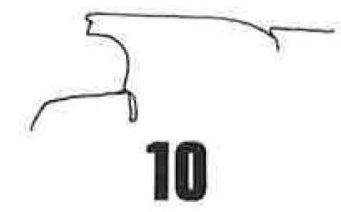

with A2-A10 dark brown. Head from above 1.9 times wider than long, slightly wider than thorax; antenna (Fig. 12) with A6-A9 each about three times as long as wide; scutellum almost as in female, but spine in lateral view not cleaved (holotype only); fore wing fully as long as whole body, 2.8 times longer than wide; hind wing 5.8 times longer than wide; metasoma hardly as long as mesosoma. Rest of characters essentially as in female.

Affinities. - Most similar to S. velutinus (Walker, 1835), but the female of this species has incomplete notauli, head 2.0 times wider than long, lateral ocelli separated from inner orbits by only half their diameter, antenna with A2 as long as A3-A4 combined, and legs partly darkened, cf. Vlug (1985).

Etymology. - Named after the famous Swedish entomologist Karl Henrik Boheman to commemorate his 200th birthday (10 July 1996).
Platygaster litoralis $\mathrm{sp} . \mathrm{n}$.

Figs. 13-17

Type material: Holotype $O$ in ZMO labeled "Norway, EIS 28, BØ, Hurum: Verks $\varnothing$ ya 6 June-8 July 1995 . L.O. Hansen/ O. Hanssen, Malaisetrap seashore", Paratypes: 4 ㅇ, 10 same data as holotype.

Diagnosis. - A species with dark antennae and legs, slender female antennae (A9 almost twice as long as wide), short notauli and female metasoma rather short but pointed at apex.

Description. - ․ Body length 1.3-1.5 mm (holotype $1.4 \mathrm{~mm}$ ). Colour blackish; antennal toruli, extreme base of scape, A2 partly, mandibles, most of fore tibiae, both ends of middle and hind tibiae, and segments $1-4$ of all tarsi reddish brown.

Head from above (Fig. 13) 2.0 times as wide as long, slightly wider than thorax; occiput with extensive but rather weak transverse striation 

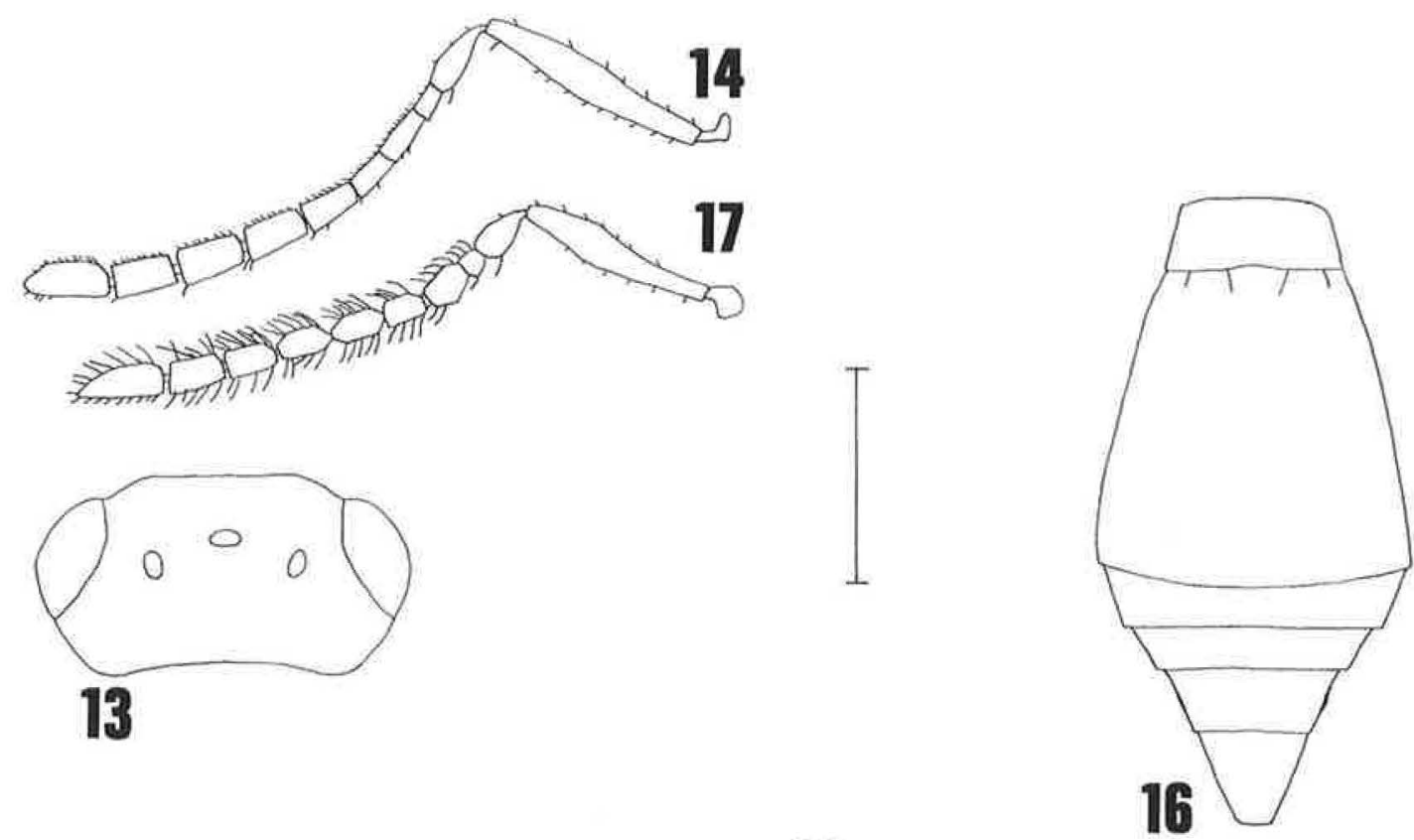

Figs. 13-17. Platygaster litoralis sp. n.: 13: Head from above,,$; 14:$ Antenna,,$; 15:$ Scutellum in lateral view, ㅇ; 16: Metasoma from above, o; 17: Antenna, o'. Scale bar $=0.25 \mathrm{~mm}$.

which is acutely curved medially, almost reaching anterior ocellus, rest of vertex faintly reticulate; frons almost smooth with a few punctures in upper half, faintly transversely sculptured below, above antennal insertions distinctly transversely striate. Head from in front 1.3 times wider than high. Malar space hardly 0.4 times the height of an eye; OOL:POL:LOL = 4:12:5. Antenna (Fig. 14) slender, A4 2.5 times, A9 fully 1.8 times longer than wide.

Mesosoma one and a quarter times longer than wide and slightly higher than wide (18:17). Sides of pronotum with sparse hairs in upper third, with longitudinal microsculpture over whole height, smooth in posterior third except for a few deeply implanted hairs. Mesoscutum rather sparsely hairy, unevenly reticulate-coriaceous, smoother on lateral lobes and posteriorly; notauli faintly indicated posteriorly, mid lobe prolonged here, almost reaching scutellum; scuto-scutellar grooves rather wide and deep, with a few long hairs. Mesopleurae almost smooth. Scutellum (Fig. 15) convex, slightly above level of mesoscutum, rather sparsely and evenly hairy, smooth except for the

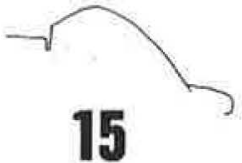

pustule-like implantations of hairs. Metapleurae reticulate, with rather sparse whitish pilosity all over. Propodeal carinae short, parallel and wide apart, area in between smooth and shiny, more than twice as wide as long.

Fore wing clear, 0.8 times as long as whole body, 2.4 times longer than wide; marginal cilia very short. Hind wing with two frenal hooks, 4.6 times longer than wide; marginal cilia 0.2 the width of the wing.

Metasoma (Fig. 16) slightly longer than head and mesosoma combined (15:14), narrower than thorax (15:17) and 1.8 times wider than high. T1 unevenly crenulated, with a few hairs laterally; T2 striated in basal foveae to half of length, medially to one-fourth of length, rest of tergite smooth; T3-T6 almost smooth and rather flattened; T3-T4 each with a transverse row of rather deeply implanted hairs which is interrupted medially, T5 with a complete such row; T6 with some scattered hairs.

Description of paratype. - $\sigma^{7}$. Body length $1.1 \mathrm{~mm}$. Antenna (Fig. 17). Metasoma shorter than head and mesosoma combined (21:24), more 
rounded at apex than in female. Rest of characters essentially as in female.

Affinities. - Rather similar to $P$. entwistlei Buhl, 1997 (Buhl 1997), but the female of this species has much less transverse $\mathrm{T} 1$ and much more transverse T3-T6 than litoralis. There are also distinct differences in the sculpture of the two species. Also similar to $P$. betularia Kieffer, 1916, but the female of this species has T6 ending in a fine point and antennae of both male and female less slender than in litoralis, cf. Roskam (1986). Runs to P. rohweri Fouts, 1924 in Fouts' (1924) key to Nearctic species, but the female of this species has A2 only as long as A6 (in litoralis A2 is about 1.4 times longer than A6), and it is a smoother and more slender species than litoralis, cf. Fouts (1924).

\section{Prosactogaster damokles sp. $\mathrm{n}$.}

Figs. 18-20

Type material: Holotype $ᄋ$ in ZMO labeled "Röa, Oslo, 22.6.1953, leg. A. Bakke". Unique.

Diagnosis. - A most distinct species on account of very long metasoma with flat T3-T6, short antennae, inconspicuously striated $\mathrm{T} 2$, and dark antennae and legs.

Description of holotype. - Q. Body length $2.1 \mathrm{~mm}$. Colour blackish brown, head black; mandibles and legs dark brown, both ends of tibiae and segments 1-4 of tarsi light brown.

Head from above (Fig. 18) 1.9 times wider than long, slightly wider than thorax; occiput moderately transversely reticulate-striated; vertex reticulate; frons almost smooth, with traces of reticulation along inner orbits, and transverse striation below eyes and above antennal insertions; head from in front 1.3 times wider than high; malar space about 0.3 the height of an eye; OOL:POL:LOL $=3: 10: 4$. Antenna (Fig. 19) with A9 slightly longer than wide (8:7).

Mesosoma one and a third times longer than wide and very slightly higher than wide. Sides of pronotum moderately hairy in upper 0.4 , with a spot of reticulation medially in upper half, rest smooth and with a few hairs. Mesoscutum rather shiny, sparsely hairy; mid lobe reticulate in anterior half, longitudinally coriaceous in posterior half; lateral lobes reticulate, smooth along lateral margins; notauli complete and deep; mid lobe prolonged posteriorly, just reaching base of scutellum; scuto-scutellar grooves rather wide and deep, covered by sparse long hairs. Mesopleurae almost smooth, with some longitudinal wrinkles in upper third. Scutellum slightly convex, hardly above level of mesoscutum, with sparse hairs and traces of reticulation. Metapleurae and sides of propodeum densely covered with white pilosity. Propodeal carinae short, parallel and wide apart, area in between more than twice as wide as long, smooth and shiny.

Fore wing clear, 2.9 times longer than wide, reaching almost to middle of $\mathrm{T} 5$; marginal cilia short. Hind wing with two frenal hooks, 6.4 times longer than wide; marginal cilia 0.3 the width of the wing.

Metasoma (Fig. 20) slightly narrower than mesosoma and 3.5 times longer (2.2 times longer than head and mesosoma combined), and 1.5 times wider than high. T1 with rather dense hairs standing out from sides, with two complete longitudinal keels and a shortened medial one, crenulated anteriorly between and lateral of keels, rest smooth. T2 one and a third times longer than wide, with deep basal foveae which are faintly striated to one-third the length of tergite, rest smooth. T3T6 with weak traces of longitudinal sculpture and with a few hairs, strongly flattened. Sternite 2 anteriorly with a long cornutus reaching mid coxae.

Affinities. - Runs to $P$. marshalli Kieffer, 1916 in Kieffer's (1926) key, but marshalli has a head much more transverse and A4 much longer than in damokles, and marshalli has T2 at least twice as long as wide. $P$. lineata (Kieffer, 1906) has T2 twice as long as wide, as long as T4-T6 combined; P. enneatomus (Kieffer, 1913) has a head differently sculptured than in damokles, A3 as thick as A2, and metasoma only 1.5 times longer than the head and mesosoma combined; P. phragmitis (Schrank, 1781) has a head more than twice as wide as long, thorax twice as long as wide and legs yellow; P. nitida (Thomson, 1859) and $P$. subuliformis Kieffer, 1926 have a differently sculptured head than in damokles, T2 striated over whole width, and metasoma only 1.75 times longer than the head and mesosoma combined; $P$. atten $u$ ata (Haliday, 1831) has brown wings and more 


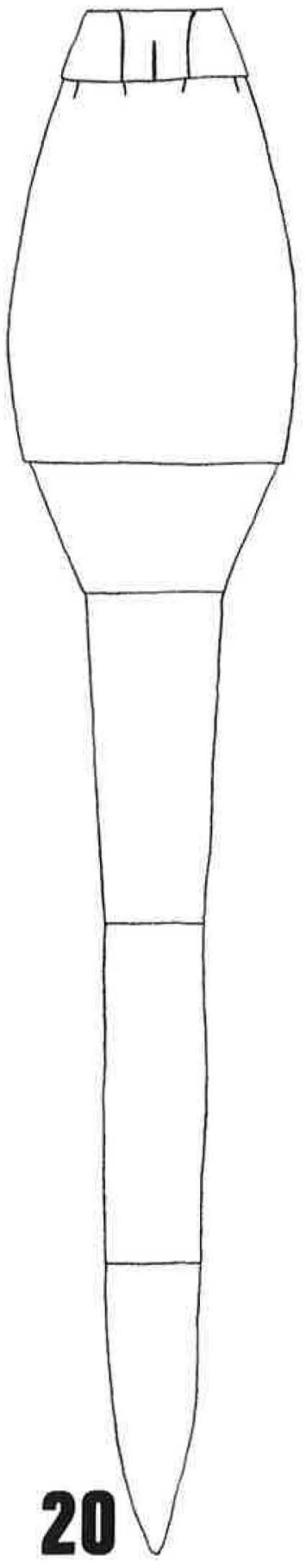

Figs. 18-20. Prosactogaster damokles sp. n. ㅇ: 18: Head from above; 19: Antenna, 20: Metasoma from above. - Scale bar $=0.25 \mathrm{~mm}$.
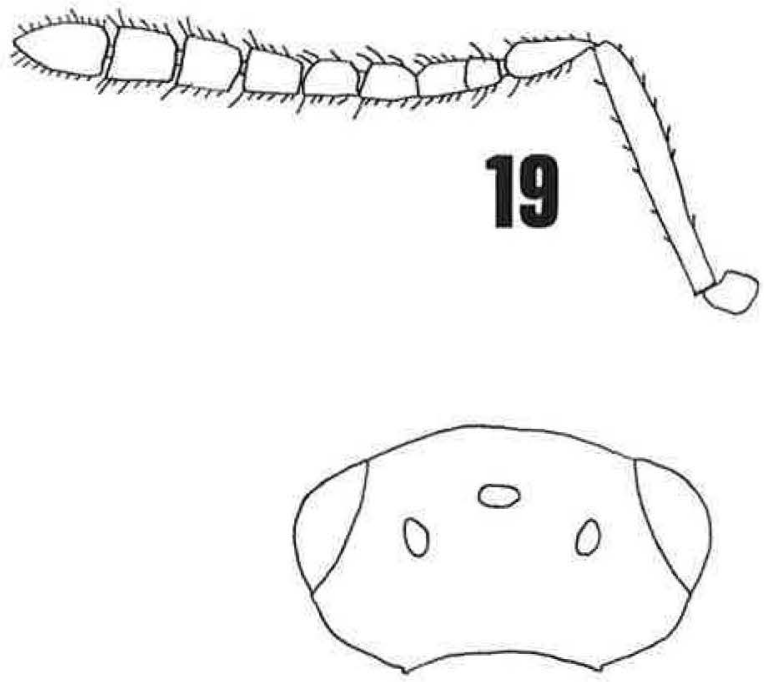

18

extensive striation on metasoma than in damokles, cf. Kieffer (1926), Szelényi (1958), and Buhl (1995). Runs to Platygaster americana (Ashmead, 1887 ) in Fouts' (1924) key to Nearctic species, but americana has much more elongate $\mathrm{T} 2$ and shorter T3-T6 than damokles, cf. Fouts (1924). Some authors consider Prosactogaster just a subgenus of Platygaster; Prosactogaster is characterized by the cornutus on sternite 2 . According to Vlug (1995), americana, phragmitis, nitida, and attenuata belong to Platygaster s. str.

Acknowledgements. I am very grateful to Mr. Lars Ove Hansen at the Zoological Museum, University of Oslo, for placing this material at my disposal.

\section{References}

Buhl, P. N. 1995: On some types of Platygaster described by J. W. Zetterstedt and C. G. Thomson (Insecta: Hymenoptera: Platygastridae: Platygastrinae). - Entomol. Abh. (Dresden) 57(1): 91-108.

Buhl, P. N. 1997: On some new or little known species of Platygastrinae (Insecta: Hymenoptera: Platygastridae). - Entomofauna 18. (In print.)

Fouts, R. M. 1924: Revision of the North American wasps of the subfamily Platygasterinae. - Proc. U.S. Natl. Mus. 63(15): 1-145.

Huggert, L. 1983: On Telenomus, mainly European; redescriptions, new taxa, synonymies and combinations 
(Hymenoptera, Proctotrupoidea: Scelionidae). Entomol. Scand. 14: 145-167.

Kieffer, J. J. 1926: Hymenoptera Proctotrupoidea. Scelionidac. - In: Das Tierreich 48. Walter de Gruyter \& Co., Berlin \& Leipzig. 885 pp.

Kozloy, M. А. (Коэлов, М. А.) 1978: Superfamily Proctotrupoidea. - In: Medvedev, G. S. (ed.), Determination of the insects of the European part of the USSR: 538664. Vol. 3, part 2. Publishing House "Nauka", Leningrad, 758 pp. (In Russian, transl. to English 1988.)

Kozlov, M. A. \& Kononova, S. V. (Козлов, M. A. \& Кононова, C. В.) 1983: [Telenominae of the SSSR.] - Opredeliteli Fauna SSSR 136. - Publishing House "Nauka", Leningrad. 336 pp. (In Russian.)

Kozlov, M. A. \& Kononova, S. V. (Козлов, M. A. \& Кононова, С. В.) 1987: [New species of telenomine egg parasites (Hymenoptera, Scelionidae, Telenominae) of the fauna of the USSR. Report 2.] — Vestn. Zool. 1987(5): 9-15. (In Russian.)

Roskam, J. C. 1986: Biosystematics of insects living in female birch catkins. IV. Egg-larval parasitoids of the genera Platygaster Latreille and Metaclisis Förster (Hy- menoptera, Platygastridae). - Tijdschr. Entomol. 129: $125-140$.

Szabó, J.B. 1978. Neue und wenig bekannte Telenomus Haliday, 1833 Arten aus dem Karpaten-becken (Hymenoptera: Scelionidae) - Folia Entomol. Hung. 31: 219-236.

Szelényi, G. 1958: Über einige durch Zucht erhaltene Scelioniden und Bethyliden (Hymenoptera). - Ann. Hist.Nat. Mus. Natl. Hung. 50: 261-270.

Thomson, C. G. 1859: Sveriges Proctotruper. Tribus VII. Platygastrini. - Öfvers. K. Vetenskapsakad. Förh. 16: 69-87.

Vlug, H. J. 1985: The types of Platygastridae (Hymenoptera, Scelionoidea) described by Haliday and Walker and preserved in the National Museum of Ireland and in the British Museum (Natural History). 2. Keys to species, redescriptions, synonymy. - Tijdschr. Entomol. 127: 179-224.

Vlug, H. J. 1995: Catalogue of the Platygastridae (Platygastroidea) of the world. - In: Hymenopterorum Catalogus Pars 19. SPB Academic Publishing bv, Amsterdam. $168 \mathrm{pp}$. 